\title{
Experiment and Modeling of Soil-Water Characteristic Curve of Unsaturated Soil in Collapsing Erosion Area
}

\author{
Weiping Liu ${ }^{1,2 *}$, Xiaoyan Luo ${ }^{1,3}$, Mingfu Fuํㅜ, Jinsong Huang ${ }^{1,2}$ \\ ${ }^{1}$ School of Civil Engineering and Architecture, Nanchang University, Nanchang 330031, China \\ ${ }^{2} \mathrm{ARC}$ Centre of Excellence for Geotechnical Science and Engineering, The University of Newcastle, \\ Callaghan, NSW 2308, Australia \\ ${ }^{3}$ Jiangxi Science and Technology Normal University, Nanchang 330013, China
}

Received: 11 April 2016

Accepted: 19 July 2016

\begin{abstract}
Soil erosion tends to occur with rainfall runoff, thus leading to grave soil and water loss. An increase of water content in soil caused by rain makes the loss of matrix suction and the decrease of shear strength obvious, and will promote soil erosion. The soil-water characteristic curve (SWCC) can be used to describe the relationship between the water content and the matrix suction in unsaturated soil. For this paper we studied the SWCCs of the granite residual soils in a collapsing erosion area in Jiangxi Province, China. A GEO-Experts pressure plate extractor was used to measure SWCCs for soils with different dry density, grain size, drying and wetting cycles, and lime content. The initial dry density has a significant impact on SWCC. With increasing dry density, the suction was decreased for the same water content. The larger the grain size, the greater the suction value for the same volumetric water content. Under the same suction, the volumetric water content decreases as the lime percentage increases and water stability improves. SWCCs of the drying and wetting cycle demonstrate the hysteresis phenomenon. The area of the hysteresis loop decreased with the increase of the dry density and drying and wetting cycle number. It also became small when the soils were mixed with lime. In this paper, the Van Genuchten model, the Fredlund and Xing model, and the Gardner model were used to fit the experimental data of SWCCs. The presented fitting parameters show that the residual sum of squares is less than 0.002. All the experimental data fit well to three models for SWCC. The results indicated that the simulated value of the Gardner model does provide best agreement with the measured value. These results will provide an important basis for the further study of the soil collapsing erosion process and soil cover design.
\end{abstract}

Keywords: soil collapsing erosion, soil-water characteristic curve, suction, granite residual soil, lime

*e-mail: wpliu@126.com 


\section{Introduction}

The relationship between water content and matrix suction in unsaturated soil is termed the soil-water characteristic curve (SWCC), which is widely used in geotechnical, geoenvironmental, and agricultural engineering [1]. SWCC is a fundamental element for characterizing the essential aspects of unsaturated soil behavior and it plays an important role in unsaturated soil mechanics. Based on the fundamental theories of unsaturated soil mechanics, the matrix suction has great influence on the engineering characteristics of unsaturated soil, including water-holding capacity, strength, permeability, and volumetric change of soil [24]. The SWCCs can also be used to reflect the ability of water retention, strength, and permeability [5]. The shear strength and matrix suction of soils have a direct relationship with water content of the soils.

If the influence of matrix suction is taken into account, the engineering behavior of soils that are typically in a state of unsaturated condition can be better interpreted [6]. Previous researchers have studied the influencing factors of the SWCC. The initial dry intensity [7-8], specimen thickness [9], initial water content [10], and grain size distribution [11] of the soils have significant influence on the SWCC. Romero [12] explored and revealed the effects of net normal stress and stress paths on SWCC. $\mathrm{Ng}$ and Leung [13] present the general behavior of the SWCC, taking into account the stress history of the soil. The saturated volumetric water contents and the air entry values of the SWCC are also affected by particle sizes [1415]. The SWCC is often the boundary conditions when the finite element method or finite difference method has been used to analyze the problem of rainfall effect.

Rainfall infiltration will result in a transient increase of water content and a reduction of suction, and as a result the shear strength of the soil is correspondingly reduced [16]. The increase of soil water content makes matrix suction loss and shear strength decreases significantly, and it will also lead to soil erosion and slope instability. As a result of rainfall infiltration, matrix suction may partially or completely disappear. Rainfall and evaporation will make the soils subject to repeated drying and wetting cycles. It will change the matrix suction of the soils, and contribute to the collapsing erosion of the slope.

Rain-induced collapsing erosion poses substantial threats and has caused severe damage in China. Collapsing erosion is common in southern China [17], particularly in subtropical regions such as Jiangxi. Rainstorms in the subtropical climate zone are strong and frequent. Soilcollapsing erosion affected by numerous factors is a complex problem [18]. Rainfall runoff leads to grave soil and water loss. The granite residual soils in collapsing erosion areas are weathered deposits and subjected to intense weathering. They exhibit fracturing, low strength, and high collapse rates. The degree of weathering will influence the engineering properties of the geomaterials [19]. Lime stabilization was often performed in order to overcome this problem. It is important to understand the fundamental behavior and properties of unsaturated soils for preventing or reducing collapsing erosion. Previous investigations of collapsing erosion mainly focused on the soil particle-size distribution [20] and landform [21]; few unsaturated mechanical studies have been carried out. The SWCC experiment in a collapsing erosion area has not been performed. The formation mechanisms of collapsing erosion in southern Jiangxi are unclear and require more research.

The on-site granite residual soils are mostly unsaturated. The collapsing erosion mechanism is associated with the engineering characteristics of unsaturated soil. The SWCC is the foundation for the research of collapsing erosion. Therefore, a pressure plate apparatus was used to determine the SWCC of the granite residual soil in the collapse erosion area of Ganzhou City in Jiangxi Province. The SWCCs of soils of varied dry densities, grain sizes, and lime contents have been measured. The Van Genuchten [22], Fredlund and Xing [5], and Gardner [23] models were used to fit the experimental data. These studies were useful for understanding some behaviors of granite residual soils and provide an important basis for the research of collapsing erosion development and soil cover design.

\section{Material and Methods}

The SWCCs were measured by means of a pressure plate extractor in this study. The GEO-Experts pressure plate extractor realized the soil specimen drying or wetting process by increasing or decreasing the matrix suction, which was based on the axis translation technique. When the suction was increased, the water was drained from the specimen through the ceramic disk until the equilibrium was reached. Once the suction was decreased, water flowed back through the ceramic disk until the equilibrium was reached. The suctions were then plotted against their corresponding water contents to obtain SWCC.

The soil samples were taken from a collapsing erosion region in Ganzhou City. The soils were collected $0.3 \mathrm{~m}$ below the surface. Basic soil properties were measured for the soils. The soil had a liquid limit of $40 \%$, a plastic limit of $27.5 \%$, and a plasticity index of 12.5 . The specific gravity was 2.73 . The maximum dry density was $1.76 \mathrm{~g} / \mathrm{cm}^{3}$.

The soil particles were first sieved by a sieve with a $2 \mathrm{~mm}$ aperture size. Those particles with a dimension larger than $2 \mathrm{~mm}$ were discarded. The experimental specimens were prepared for the dry densities of $1.45 \mathrm{~g} / \mathrm{cm}^{3}, 1.50 \mathrm{~g} / \mathrm{cm}^{3}, 1.55 \mathrm{~g} / \mathrm{cm}^{3}$, and $1.65 \mathrm{~g} / \mathrm{cm}^{3}$. The effect of lime on SWCC was also investigated with the following percentages using $0 \%, 4 \%$, and $6 \%$ lime. These were based on the same dry density of $1.45 \mathrm{~g} / \mathrm{cm}^{3}$. In order to analyze the influence of grain size, the particles that were also sieved by a sieve with a $1 \mathrm{~mm}$ aperture size were made into soil specimens with a dry density of $1.55 \mathrm{~g} / \mathrm{cm}^{3}$. In this study, the SWCCs were obtained following the drying or wetting path in the suction range of $0-400 \mathrm{kPa}$. 
The specimens were first prepared at an initial gravimetric water content of $w=20 \%$ and a given dry density $\rho_{d}$. The specimens were prepared using a cutting ring of $70 \mathrm{~mm}$ in diameter and $19 \mathrm{~mm}$ in height. In order to ensure uniform specimens with fewer clay clusters, the $19 \mathrm{~mm}$ high specimen was statically compacted to the target dry densities in three layers. The soil specimens were saturated using the vacuum saturation method. For the granite residual soil, tests of the SWCCs were divided into four test groups. One group of specimens W1, W2, W3, and W4 were saturated allowing dry density change and used to compare the influence of different initial dry density on SWCCs. The second group specimens (W4, W5, and W6) changed the lime content with the same dry density of $1.45 \mathrm{~g} / \mathrm{cm}^{3}$. The third group specimens (W3 and W7) choose different grain sizes ( $1 \mathrm{~mm}$ and $2 \mathrm{~mm})$. W1, W3, and $\mathrm{W} 7$ were used to compare the influence of the drying and wetting cycles of SWCC. Two drying and wetting cycles were measured for two specimens of W1 and W6 in this test. Detailed test schemes are shown in Table 1.

\section{Results and Discussion}

\section{Effect of Dry Density on SWCC}

Several tests were carried out on granite residual soil specimens under different initial dry densities of 1.45 , $1.50,1.55$, and $1.65 \mathrm{~g} / \mathrm{cm}^{3}$. The drying SWCCs of different dry density soil were illustrated in Fig. 1. The shapes of SWCC are similar, and depend on the dry density of soil specimens. The soil with the greater dry density has a smaller initial water content. It can be observed that for the same soil with different dry density, during the drying process the volumetric water contents were reduced with increasing matrix suction. Under the same water content, the matrix suction decreased when dry density increased. The discharge rate of water content tends to be slow with the increasing matrix suction. In the high suction portion of the SWCC, the volumetric water contents of different drying densities are close. The lower initial dry density

Table 1.Test schemes.

\begin{tabular}{|c|c|c|c|c|}
\hline Sample & $\begin{array}{c}\text { Dry } \\
\text { density } \\
\left(\mathrm{g} / \mathrm{cm}^{3}\right)\end{array}$ & $\begin{array}{c}\text { Lime } \\
\text { content } \\
(\%)\end{array}$ & $\begin{array}{c}\text { Grain } \\
\text { size } \\
(\mathrm{mm})\end{array}$ & $\begin{array}{c}\text { Experiment } \\
\text { method }\end{array}$ \\
\hline W1 & 1.45 & 0 & 2 & $\begin{array}{c}\text { Drying-wetting } \\
\text { twice }\end{array}$ \\
\hline W2 & 1.50 & 0 & 2 & Drying \\
\hline W3 & 1.55 & 0 & 2 & $\begin{array}{c}\text { Drying-wetting } \\
\text { once }\end{array}$ \\
\hline W4 & 1.65 & 0 & 2 & Drying \\
\hline W5 & 1.45 & 4 & 2 & Drying \\
\hline W6 & 1.45 & 6 & 2 & $\begin{array}{c}\text { Drying-wetting } \\
\text { twice }\end{array}$ \\
\hline W7 & 1.55 & 0 & 1 & Drying \\
\hline
\end{tabular}

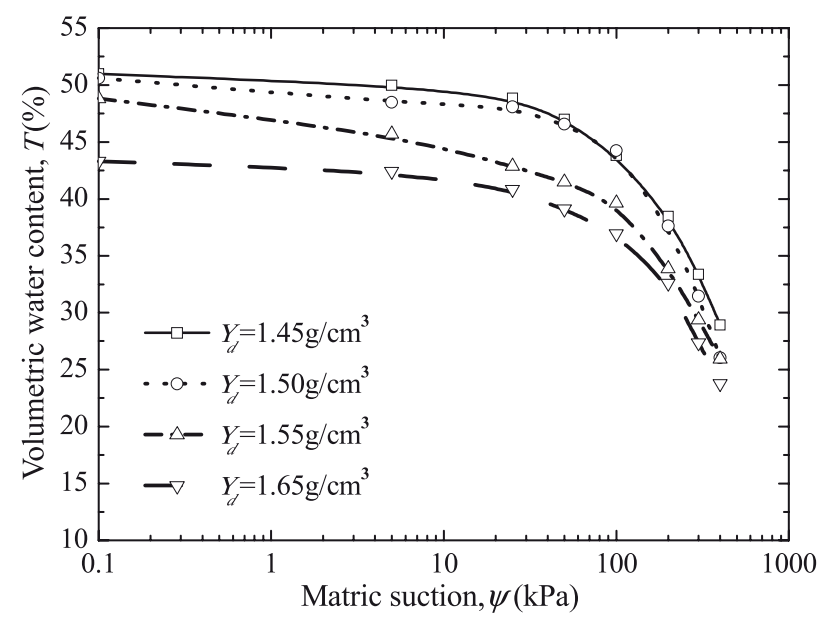

Fig. 1. Drying SWCCs of different dry density soils.

specimens have larger volume water content, and air entry values are lower than higher dry density ones. The total amount of pore voids of soils will vary because of the change of dry density. Due to the higher dry density, the soil is more compact and of smaller porosity, and its water retention ability increases. The pore water in the soil specimen of high dry density is not easy to discharge. The air entry value of the SWCC is large with high dry density. When pore air pressure is larger than the air entry value, the matrix suction will nearly linearly increase as water content decreases. When the suction is great, the SWCC of different dry densities have a tendency to gather together. The SWCC is less sensitive to density changes at high suction, and that is contrary for low suction. The matrix suction obviously changes along with the water content, and it decreases with the increase of water content. So the rainfall will cause an increase of water content and lead to stress redistribution in the soil so as to promote slope erosion or instability.

\section{Effect of Grain Size on SWCC}

The SWCCs of the soil particles that were sieved with a $2 \mathrm{~mm}$ aperture size sieve and $1 \mathrm{~mm}$ aperture size sieve are shown in Fig. 2. To examine the effects of grain size, we considered the drying SWCCs obtained for the two specimens with the same dry density of $1.55 \mathrm{~g} / \mathrm{cm}^{3}$. Through comparison analysis of the test results of different grain sizes relative to SWCC of the large grain size soils (sieved with a $2 \mathrm{~mm}$ sieve), the SWCC of small grain size soils (sieved with a $1 \mathrm{~mm}$ sieve) in aforesaid SWCC is obvious in the lower position of the low matrix suction. The saturation volume water content of the large grain size soil is greater than that of the small grain size. Under the same volume water content, the suction of the large grain size soil is higher than that of the small grain size soils. The air entry value of the SWCC of the large grain size soils is smaller than that of small grain size soil. This is due to the size of the pore being larger in the large grain-size soils. When the suction is high, SWCCs of two size soil almost overlap. 


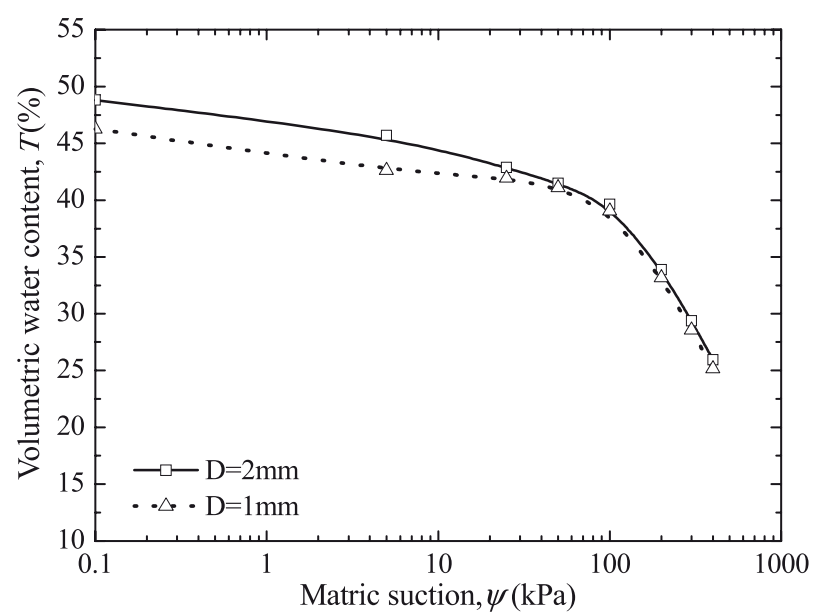

Fig. 2. SWCCs of different grain size soils.

\section{Effect of Lime Content on SWCC}

The engineering properties of soils were conventionally improved with additives such as lime. Under the conditions of the same dry density $1.45 \mathrm{~g} / \mathrm{cm}^{3}$, SWCCs of different lime contents $(0 \%, 4 \%, 6 \%)$ are shown in Fig. 3. The SWCCs of the three different lime contents were also measured in the suction range of $0-400 \mathrm{kPa}$. In the case of lime-treated soils, the volumetric water contents decreased when the percentage of lime increased for a given suction. The influence of lime on SWCCs is great. The lime is in powder form and alters the particle and pore-size distribution of soil. The particles at contact points bind more finely. The air-entry value for lime-treated soil with a higher percentage of limes is typically larger than the other with no lime. As the percentage of lime is increased, the air entry value will increase. The effect of lime at high suction was limited. In general, SWCCs are affected by lime content.

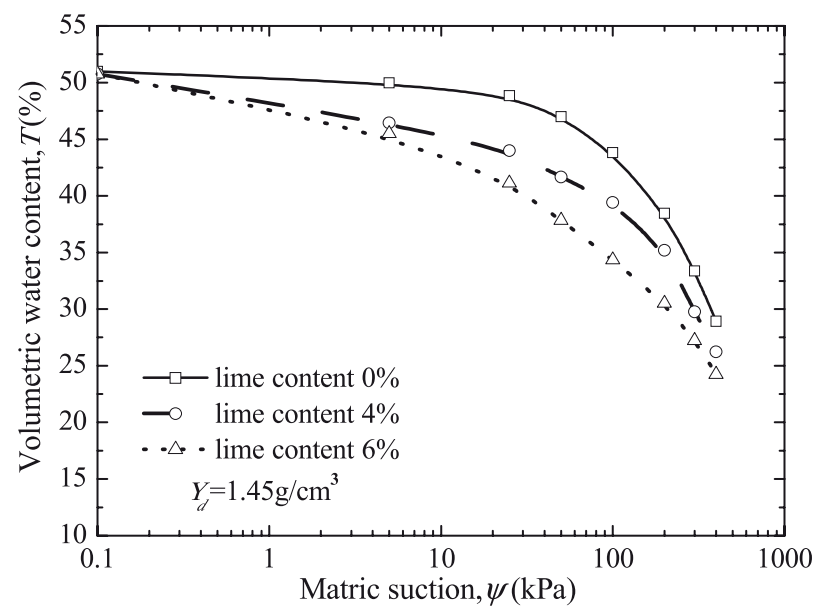

Fig. 3. Drying SWCCs of different content lime soils.

\section{Effect of Drying and Wetting Cycle}

This group has three specimens: dry density $\rho_{d}=1.45 \mathrm{~g} / \mathrm{cm}^{3}$ without lime, dry density $\rho_{d}=1.55 \mathrm{~g} / \mathrm{cm}^{3}$ without lime, and dry density $\rho_{d}=1.45 \mathrm{~g} / \mathrm{cm}^{3}$ with $6 \%$ lime. The drying and wetting cycle tests of the SWCCs of the three soil specimens were performed in the laboratory (Fig. 4). The SWCCs of three specimens have similar shapes. The volumetric water content changes with suction during drying and wetting tests. Drying and wetting curves of the same specimen do not overlap and instead form a hysteresis loop. Because the drying process changes the original soil sample properties, soils cannot return to the original state after the wetting process. With the same water content, the matrix suction in the drying process is greater than that in the wetting process. For a given matrix suction, the soil has generally higher volumetric water content in the drying process than that in the wetting process. The drying-wetting curve includes a significant hysteresis effect. In addition, each drying and wetting curve is nonlinear in shape. The SWCCs of the wetting process are gentle compared with dry density. The increasing ratio during the drying process is larger than that during the wetting process.

Through a comparison of the SWCCs of dry densities $1.45 \mathrm{~g} / \mathrm{cm}^{3}$ and $1.55 \mathrm{~g} / \mathrm{cm}^{3}$ the hysteresis loop of dry density $1.55 \mathrm{~g} / \mathrm{cm}^{3}$ is smaller and moves down in Fig. 4. The reason is that soil becomes more dense as dry density increases. Moisture in the soil is difficult to migrate. As we also see in Fig. 4, compared with SWCCs of soil specimens, 1.45 $\mathrm{g} / \mathrm{cm}^{3}$ mixed with $0 \%$ and $6 \%$ lime content, the SWCC of lime treatment also moved down obviously because of the effect of lime. The hysteresis loops are similar to those of the dry density $1.55 \mathrm{~g} / \mathrm{cm}^{3}$ specimen. Therefore, SWCC of the low dry density and lime treatment soil can become close to that of higher density soil through adding different contents of lime. The hysteresis phenomenon of lime treatment becomes not obvious because of the effect of lime. So we know that the soil properties can be improved by adding a certain amount lime.

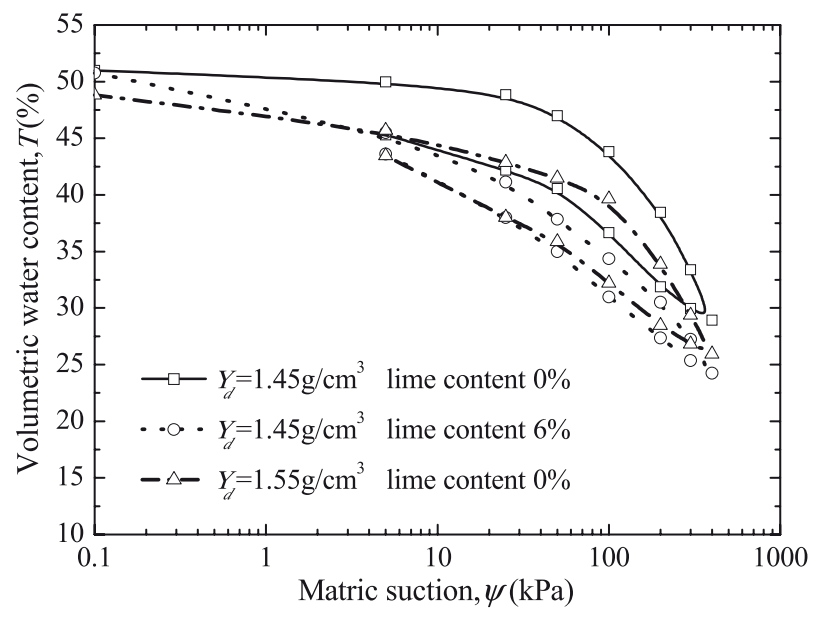

Fig. 4. Drying and wetting cycle SWCCs. 
In order to examine the effects of a number of drying and wetting cycles, the drying and wetting SWCCs were obtained for soils without lime and mixed with $6 \%$ lime, as shown in Fig. 5:

Fig. 5a: SWCC of twice-over drying and wetting cycle with dry density $1.45 \mathrm{~g} / \mathrm{cm}^{3}$. The measured results show that the drying and wetting cycles have an obvious effect on SWCC. The results of two drying and wetting cycles are different. It can also be seen that the water content in the drying process is higher than that in the wetting process at the same suction when the process is in the same cycle. There is a marked hysteresis between the drying and wetting curves. The area of hysteresis loop of the second drying and wetting cycles becomes smaller than the first. The hysteresis becomes less significant during the second cycle. Relative to the drying and wetting cycle of the first time, the matrix suction of the cycle of the second time decreases significantly. The hysteresis potential is reduced as the number of drying and wetting cycles increases. This is because the structure of the soils changes and porosity decreases after the first drying and wetting cycles.

Fig. 5b: SWCC of twice-over drying and wetting cycles of dry density $1.45 \mathrm{~g} / \mathrm{cm}^{3}$ plus $6 \%$ lime content. The difference between SWCCs of the first and second drying and watering cycles becomes small. Comparing Figs 5a and $b$, the two SWCCs have obvious differences. The
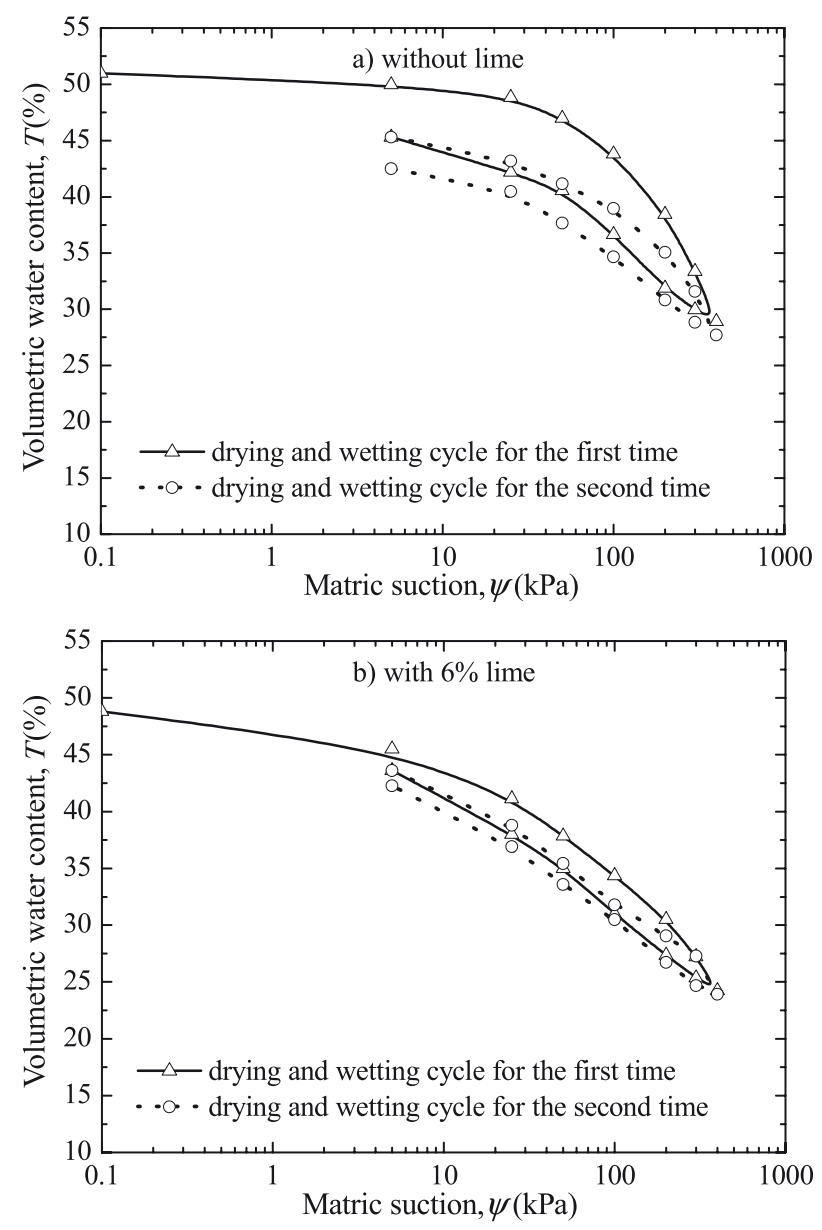

Fig. 5. SWCCs of twice drying and wetting cycles.
SWCC hysteresis loop mixed with $6 \%$ lime is significantly smaller than that without lime. This phenomenon is mainly caused by the lime. The hysteresis between the drying and wetting cycle curves of the specimen with the lime-treated soil is more stable. In other words, the structure of the soil structure tends to be more stable when mixed with lime. The lime occupies their voids and bond particles more finely at contact points. The pore void distribution of soils is reduced. So the lime can improve the soil properties.

\section{Model for SWCC}

Scholars put forward many different soil-water characteristic curve models for SWCC research [5, 2223]. The interaction between soil and water is relatively complex. Many models have been proposed for fitting analytical functions through experimental results. Three models such as the Van Genuchten, Fredlund and Xing, and Gardner models were chosen to fit experimental data of SWCC in this paper. We compared three common models to evaluate which one is better for soils in a collapsing erosion area. The equations of the discussed models can be expressed in the following forms:

Van Genuchten model [22]

$$
\theta_{w}=\theta_{r}+\frac{\theta_{s}-\theta_{r}}{\left[1+(a \psi)^{n}\right]^{\left(1-n^{-1}\right)}}
$$

Fredlund and Xing model [5]

$$
\theta_{w}=\theta_{r}+\frac{\theta_{s}-\theta_{r}}{\left[\mathrm{~h}\left(e+(a \psi)^{n}\right)\right]^{n}}
$$

Gardner model [23]

$$
\theta_{w}=\theta_{r}+\frac{\theta_{s}-\theta_{r}}{1+a \psi^{b}}
$$

...where $\theta_{w}$ is the volumetric water content, $\theta_{s}$ is the saturated volumetric water content (volumetric water content at suction $=0 \mathrm{kPa}), \theta_{r}$ is the residual volumetric water content, $\psi$ is the matrix suction $(\mathrm{kPa})$, and $a, b, n$, and $m$ are the shape parameters of SWCC.

Based on the above models, the Matlab and nonlinear least-squares algorithm were used to fit experimental data. A more suitable SWCC model in collapsing erosion area can be obtained through comparing the fitting parameters. SWCC is an important tool to describe unsaturated soil properties. The fitting parameters accuracy of unsaturated soil has great impact on the precision of the geotechnical engineering numerical simulation [24]. The parameters of three different functions used to fit the measured data of the SWCC tests are presented in Table 2, which shows that the residual sum of squares (RSS) in each model (Van Genuchten, Fredlund and Xing, and Gardner) is small 
Table 2. Fitting parameters of SWCCs.

\begin{tabular}{|c|c|c|c|c|c|c|c|c|c|c|}
\hline \multirow{2}{*}{ Sample number } & \multicolumn{2}{|c|}{ Van Genuchten model } & \multicolumn{3}{|c|}{ Fredlund and Xing model } & \multicolumn{4}{c|}{ Gardner model } \\
\cline { 2 - 11 } & $\mathrm{a}$ & $\mathrm{n}$ & $\mathrm{RSS}$ & $\mathrm{a}$ & $\mathrm{n}$ & $\mathrm{m}$ & $\mathrm{RSS}$ & $\mathrm{a}$ & $\mathrm{b}$ & RSS \\
\hline W1-1 & 0.0059 & 1.4979 & 0.0002 & 0.0031 & 0.0621 & 1.0503 & 0.0000 & 0.0026 & 1.2580 & 0.0001 \\
\hline W1-2 & 0.0197 & 1.3632 & 0.0001 & 0.0261 & 0.0181 & 1.0065 & 0.0001 & 0.0074 & 1.1046 & 0.0001 \\
\hline W1-3 & 0.0074 & 1.4117 & 0.0003 & 0.0052 & 0.0353 & 1.0273 & 0.0002 & 0.0023 & 1.0695 & 0.0002 \\
\hline W1-4 & 0.0216 & 1.3474 & 0.0000 & 0.0270 & 0.0162 & 1.0062 & 0.0000 & 0.0077 & 1.0858 & 0.0000 \\
\hline W2 & 0.0044 & 1.6531 & 0.0004 & 0.0011 & 0.1441 & 1.1438 & 0.0003 & 0.0024 & 1.5435 & 0.0001 \\
\hline W3-1 & 0.0097 & 1.2815 & 0.0012 & 0.0079 & 0.0341 & 1.0180 & 0.0009 & 0.0012 & 0.7913 & 0.0007 \\
\hline W3-2 & 0.0453 & 1.3810 & 0.0001 & 0.0743 & 0.0151 & 1.0081 & 0.0001 & 0.0119 & 0.7678 & 0.0001 \\
\hline W4 & 0.0058 & 1.5206 & 0.0004 & 0.0029 & 0.1914 & 1.0914 & 0.0001 & 0.0017 & 1.1059 & 0.0002 \\
\hline W5 & 0.0146 & 1.1495 & 0.0016 & 0.0121 & 0.0289 & 1.0180 & 0.0015 & 0.0007 & 0.6486 & 0.0008 \\
\hline W6-1 & 0.0699 & 1.1709 & 0.0012 & 0.0648 & 0.0187 & 1.0112 & 0.0010 & 0.0021 & 0.5195 & 0.0002 \\
\hline W6-2 & 0.0425 & 1.4492 & 0.0001 & 0.0770 & 0.0165 & 1.0094 & 0.0000 & 0.0130 & 0.8069 & 0.0000 \\
\hline W6-3 & 0.0435 & 1.3190 & 0.0003 & 0.0594 & 0.0164 & 1.0066 & 0.0003 & 0.0069 & 0.6151 & 0.0002 \\
\hline W6-4 & 0.0450 & 1.4409 & 0.0001 & 0.0824 & 0.0156 & 1.0089 & 0.0000 & 0.0126 & 0.7339 & 0.0000 \\
\hline W7 & 0.0061 & 1.5237 & 0.0009 & 0.0034 & 0.0530 & 1.0407 & 0.0007 & 0.0033 & 1.3963 & 0.0009 \\
\hline
\end{tabular}

Note: residual sum of squares abbreviation for RSS, Wi-1 is the drying process of Sample i for the first time; Wi-2 is the wetting process of Sample $i$ for the first time; Wi-3 is the drying process of Sample $i$ for the second time; Wi-4 is the wetting process of Sample i for the second time.

and less than 0.002 . It can be noted that all parameters match well with those obtained for individual specimens. The three models can fit SWCC well. The fitted SWCC of different models are roughly similar. By comparing and analyzing the fitting parameters of the three models, the residual sum of squares of the Gardner model is less than that of the Van Genuchten and Fredlund and Xing models. So the Gardner model is better than the other models for fitting the experimental data. The fitting curves are shown in Fig. 6. By observing the degree of similarity of the fitting curves in Fig. 6, we can also see that the Gardner model fitting curves are closest to the experimental results. In general, the fits to experimental data provided by the three models were similar. The fitting parameters of SWCC can provide the foundation for collapsing the erosion process analysis.

\section{Conclusions}

This paper presents experimental and analytical model studies of SWCC of natural and lime-treated soils. SWCC

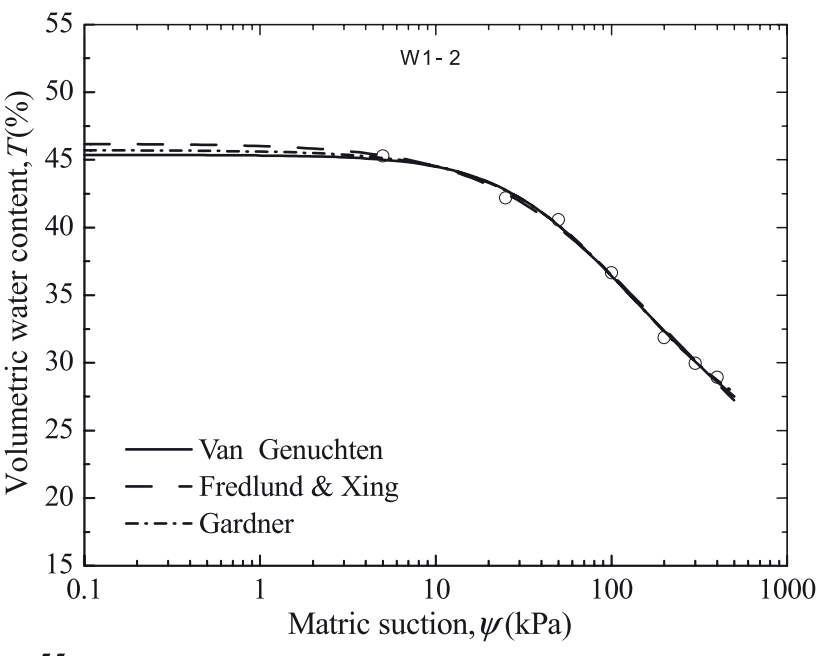

Fig. 6. The fitting of SWCCs. 

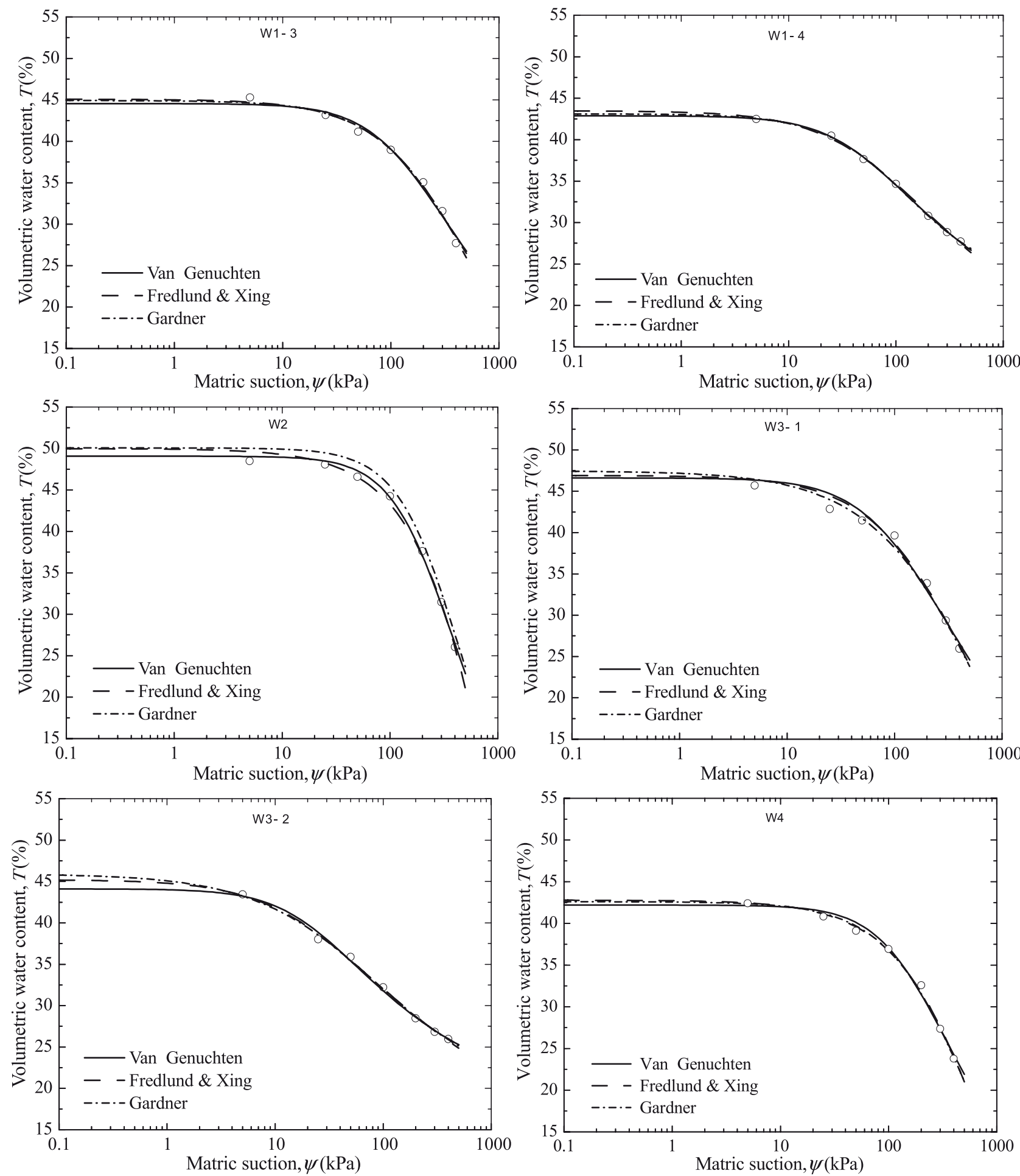

Fig. 6. Continued.

plays an important role in engineering properties of unsaturated soil. The investigations demonstrate that the shapes of SWCCs of granite residual soils are correlated to dry density, grain size, lime content, and drying and wetting cycles.

1. SWCC values for shallow soils in collapsing erosion area are derived through the SWCC laboratory tests. The matrix suction is closely relevant to water content and it decreases with increasing water content. So rainfall will cause an increase in soil water content and the shear strength of unsaturated soil will be significantly reduced. This will cause the collapsing erosion to develop more quickly. Correct valuation of SWCCs of collapsing erosion soil provides a theoretical foundation for the study of the soil collapsing erosion mechanism.

2. The SWCC in the collapsing erosion area is influenced by many factors and exhibits hysteresis 

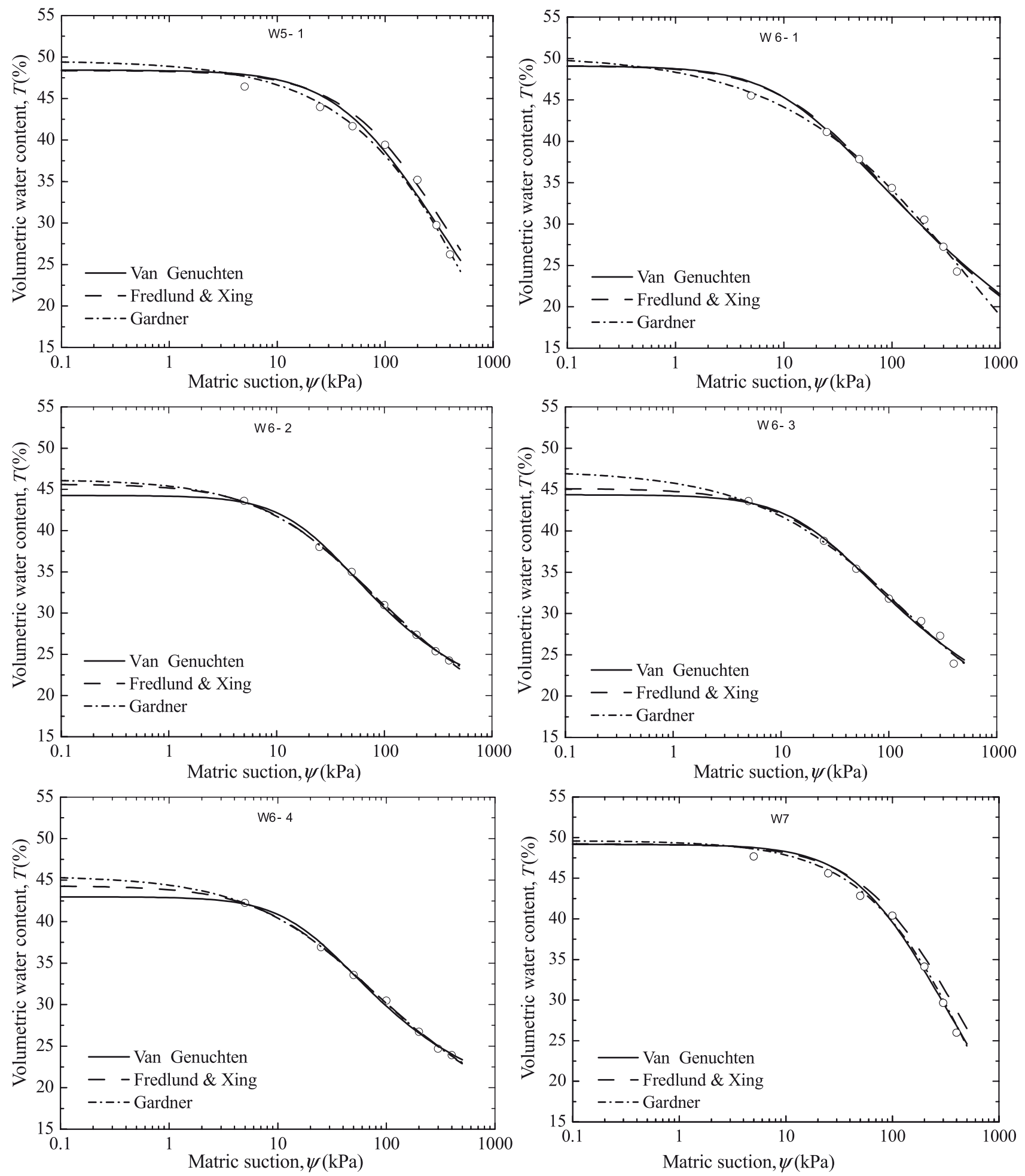

Fig. 6. Continued.

between drying and wetting curves. From those experiments, the most significant influence on SWCC is dry density. Dry density not only affects the fitting parameters, but also affects the slope of SWCC, the initial volume water content, and residual volume water content.

3. Lime can change the characteristics of soil. The volumetric water contents of lime-treated soils decrease with increases in percentage of lime under the same suction. The SWCCs of the low dry density soil when mixed with lime and of higher density soils can be close. The hysteresis phenomenon becomes insignificant because of the effect of lime. The SWCC is a useful tool to understand lime's effect on the granite residual soil. The studies can be extended to better understand the engineering behavior of the 
natural and lime-treated granite residual soil, and it will provide a new way to evaluate the improvement effect.

4. Three fitting models were used to fit the experimental SWCC data. Interesting agreements were obtained between the prediction by three models and the experimental data. The Gardner model fit the experimental data better than the others, and it was also found to be the suitable model for the SWCC of the granite residual soil in the collapsing erosion area.

\section{Acknowledgements}

The authors gratefully acknowledge financial support from the National Natural Sciences Foundation of China (Nos. 51468041, 51268046, and 11362016).

\section{References}

1. SHENG D., GENS A., FREDLUND D.G., SLOAN S.W. Unsaturated soils: From constitutive modelling to numerical algorithms. Computers and Geotechnics, 35 (6), 810, 2008.

2. LI X., LI J.H., ZHANG L.M. Predicting bimodal soil-water characteristic curves and permeability functions using physically based parameters. Computers and Geotechnics, 57, 85, 2014.

3. RAO B.H., SINGH D.N. Establishing Soil-Water Characteristic Curve of a Fine-Grained Soil from Electrical Measurements. Journal of Geotechnical and Geoenvironmental Engineering, 136 (5), 751, 2010.

4. SEDANO J.A.I., VANAPALLI S.K. Experimental investigation of the relationship between the critical state shear strength of unsaturated soils and the soil-water characteristic curve. International Journal of Geotechnical Engineering, 5 (1), 1, 2011.

5. FREDLUND D.G., XING A. Equations for the soil-water characteristic curve. Canadian Geotechnical Journal, 31 (4), $521,1994$.

6. FREDLUND D.G., HOUSTON S.L. Interpretation of soilwater characteristic curves when volume change occurs as soil suction is changed. In Advances in Unsaturated Soils - Proceedings of the $1^{\text {st }}$ Pan-American Conference on Unsaturated Soils, 15, 2013.

7. ZHOU W., YUEN K., TAN F. Estimation of soil-water characteristic curve and relative permeability for granular soils with different initial dry densities. Engineering Geology, 179, 1, 2014.

8. JACINTO A.C., VILLAR M.V., G MEZ-ESPINA R., LEDESMA A. Adaptation of the van Genuchten expression to the effects of temperature and density for compacted bentonites. Applied Clay Science, 42 (3-4), 575, 2009.

9. IYER K., JAYANTH S., GURNANI S., SINGH D.N. Influence of Initial Water Content and Specimen Thickness on the SWCC of Fine-Grained Soils. International Journal of Geomechanics, 13 (6), 894, 2013.

10. SUN W., SUN D., FANG L., LIU S. Soil-water characteristics of Gaomiaozi bentonite by vapour equilibrium technique. Journal of Rock Mechanics and Geotechnical Engineering Geology, 6 (48-54), 2014.

11. GALLAGE C.P.K., UCHIMURA T. Effects of dry density and grain size distribution on soil-water characteristic curves of sandy soils. Soils and Foundations, 50 (1), 161, 2010.

12. ROMERO E., DELLA V.G., JOMMI C. An insight into the water retention properties of compacted clayey soils. Geotechnique, 61 (4), 313, 2011.

13. NG C.W.W., LEUNG A.K. In-situ and laboratory investigations of stress-dependent permeability function and SDSWCC from an unsaturated soil slope. Geotechnical Engineering Journal of the SEAGS \& AGSSEA, 43 (1), 26, 2012.

14. RAHARDJO H., SATYANAGA A., D'AMORE G.A.R., LEONG E.-C. Soil-water characteristic curves of gap-graded soils. Engineering Geology, 125, 102, 2012.

15. SATYANAGA A., RAHARDJO H., LEONG E.-C., WANG J.-Y. Water characteristic curve of soil with bimodal grainsize distribution. Computers and Geotechnics, 48, 51, 2013.

16. JADCZYSZYN J., NIEDŹWIECKI J. Relation of saturated hydraulic conductivity to soil losses. Polish Journal of Environmental Studies, 14 (4), 431, 2015.

17. LIU X., TANG C., ZHANG D. Simulated runoff processes on colluvial deposits of Liantanggang Benggang and their water distributions. Transactions of the Chinese Society of Agricultural Engineering 31 (11), 179, 2015.

18. VULEVIĆ T., DRAGOVIĆ N., KOSTADINOV S., SIMIĆ S. B., MILOVANOVIĆ I. Prioritization of soil erosion vulnerable areas using multi-criteria analysis methods. Polish Journal of Environmental Studies, 24 (1), 317, 2015.

19. HUANG X., WANG C., WANG T., ZHANG Z. Quantification of geological strength index based on discontinuity volume density of rock masses. International Journal of Heat and Technology, 33 (4), 255, 2015.

20. XIA D., DENG Y., WANG S., DING S., CAI C. Fractal features of soil particle-size distribution of different weathering profiles of the collapsing gullies in the hilly granitic region, south China. Natural Hazards, 79 (1), 455, 2015.

21. LIU X., LIAN H. Distribution choices of elevation and slope orientation of collapsing hills. Bulletin of Soil and Water Conservation, 31 (4), 32, 2011.

22. GENUCHTEN M.T.V. A closed-form equation for predicting the hydraulic conductivity of unsaturated soils. Soil science society of America journal, 44 (5), 892, 1980.

23. GARDNER W.R. Some steady state solutions of the unsaturated moisture flow equation with application to evaporation from a water table. Soil Science, 85 (4), 228, 1958.

24. PHOON K.K., SANTOSO A., QUEK S.T. Probabilistic Analysis of Soil-Water Characteristic Curves. Journal of Geotechnical and Geoenvironmental Engineering, 136 (3), $445,2010$. 